\title{
A points-based algorithm for prognosticating clinical outcome of Chiari malformation Type I with syringomyelia: results from a predictive model analysis of 82 surgically managed adult patients
}

\author{
Sumit Thakar, MCh, ${ }^{1}$ Laxminadh Sivaraju, MCh, ${ }^{1}$ Kuruthukulangara S. Jacob, MD, PhD, ${ }^{2}$ \\ Aditya Atal Arun, MBBS, ${ }^{1}$ Saritha Aryan, MS, MCh, ${ }^{1}$ Dilip Mohan, MS, MCh, DNB, ${ }^{1}$ \\ Narayanam Anantha Sai Kiran, MCh, ${ }^{1}$ and Alangar S. Hegde, MCh, PhD ${ }^{1}$
}

'Department of Neurological Sciences, Sri Sathya Sai Institute of Higher Medical Sciences, Bangalore; and 'Department of Psychiatry, Christian Medical College, Vellore, India

OBJECTIVE Although various predictors of postoperative outcome have been previously identified in patients with Chiari malformation Type I (CMI) with syringomyelia, there is no known algorithm for predicting a multifactorial outcome measure in this widely studied disorder. Using one of the largest preoperative variable arrays used so far in CMI research, the authors attempted to generate a formula for predicting postoperative outcome.

METHODS Data from the clinical records of 82 symptomatic adult patients with CMI and altered hindbrain CSF flow who were managed with foramen magnum decompression, C-1 laminectomy, and duraplasty over an 8-year period were collected and analyzed. Various preoperative clinical and radiological variables in the 57 patients who formed the study cohort were assessed in a bivariate analysis to determine their ability to predict clinical outcome (as measured on the Chicago Chiari Outcome Scale [CCOS]) and the resolution of syrinx at the last follow-up. The variables that were significant in the bivariate analysis were further analyzed in a multiple linear regression analysis. Different regression models were tested, and the model with the best prediction of CCOS was identified and internally validated in a subcohort of 25 patients.

RESULTS There was no correlation between CCOS score and syrinx resolution $(p=0.24)$ at a mean \pm SD follow-up of $40.29 \pm 10.36$ months. Multiple linear regression analysis revealed that the presence of gait instability, obex position, and the M-line-fourth ventricle vertex (FVV) distance correlated with CCOS score, while the presence of motor deficits was associated with poor syrinx resolution $(p \leq 0.05)$. The algorithm generated from the regression model demonstrated good diagnostic accuracy (area under curve 0.81), with a score of more than 128 points demonstrating $100 \%$ specificity for clinical improvement (CCOS score of 11 or greater). The model had excellent reliability $(\kappa=0.85)$ and was validated with fair accuracy in the validation cohort (area under the curve 0.75).

CONCLUSIONS The presence of gait imbalance and motor deficits independently predict worse clinical and radiological outcomes, respectively, after decompressive surgery for CMI with altered hindbrain CSF flow. Caudal displacement of the obex and a shorter M-line-FVV distance correlated with good CCOS scores, indicating that patients with a greater degree of hindbrain pathology respond better to surgery. The proposed points-based algorithm has good predictive value for postoperative multifactorial outcome in these patients.

https://thejns.org/doi/abs/10.3171/2017.5.SPINE17264

KEY WORDS algorithm; predictive model analysis; postsurgical improvement; outcome; Chiari Type I malformation; congenital; syringomyelia

ABBREVIATIONS AUC = area under the curve; CCOS = Chicago Chiari outcome scale; CMI = Chiari malformation Type I; FM = foramen magnum; FVV = fourth ventricle vertex; ICV = intracranial volume; PFV = posterior fossa volume; PSM = predictive statistical modeling; ROC = receiver operating characteristic.

SUBMITTED March 2, 2017. ACCEPTED May 22, 2017.

INCLUDE WHEN CITING Published online November 10, 2017; DOI: 10.3171/2017.5.SPINE17264. 
$\mathrm{P}$ OSTSURGICAL outcome research has been gaining popularity for Chiari malformation Type I (CMI), a common and frequently incapacitating neurosurgical condition. Traditionally, syrinx resolution and neurological improvement, and more recently, patient-perceived measures, have been the outcome end points after surgery for CMI. Given the complexity of clinical outcomes and the numerous variables that have been postulated to influence outcome in CMI, it is surprising that so far the utility of predictive statistical modeling (PSM) has been underexplored in CMI. A PSM-based algorithm for postoperative improvement would allow for evidence-based preoperative counseling and possibly enhance patient-perceived satisfaction from surgery. ${ }^{26}$ The objective of our study was to generate an algorithm from a predictive analysis of a large number of clinical and radiological variables to prognosticate postoperative improvement in a multifactorial outcome measure in a subset of CMI patients.

\section{Methods \\ Patient Population}

A total of 120 symptomatic patients with CMI and syringomyelia who were treated with foramen magnum (FM) decompression, C-1 laminectomy, and duraplasty at our institution over an 8-year period (2007-2014) were screened. Of these patients, 82 consecutive adult patients with altered hindbrain CSF flow (defined as decreased or absent dorsal and/or ventral biphasic CSF flow on cine MRI) and a minimum follow-up of 6 months were included in this retrospective study. Exclusion criteria included previous surgery for CMI, associated craniovertebral junction anomalies (e.g., atlantoaxial dislocation, basilar invagination, or occipitalization of the atlas), hydrocephalus, tethered cord, and scoliosis with curvature more than $20^{\circ}$.

\section{Surgical Procedure}

All patients underwent a standardized procedure. This included $3 \times 3-\mathrm{cm}$ suboccipital craniectomy that included the FM rim, C-1 laminectomy, and intradural exploration for arachnoid adhesions in the fourth ventricular outlet when CSF movement in the cisterna magna or CSF outflow from the fourth ventricle appeared to be insufficient. Tonsillar shrinkage was done when CSF flow was felt to be insufficient even after removing arachnoidal adhesions. Duraplasty was performed in all cases with pericranium or an artificial dural substitute (Surgiwear G-patch). Steroids were not administered to any patients. All surgeries were performed by faculty surgeons trained at our institution, indicating that the patient group underwent uniform application of a specific CMI surgery.

\section{Preoperative Evaluation}

Selection of patients with altered hindbrain CSF flow on cine MRI and the measured clinical and radiological variables was performed by 2 independent observers (S.T. and L.S.). The mean values of their recordings of the study cohort were used in the analysis. The various preoperative clinical variables used in the analysis included age, sex, body mass index, duration of symptoms, presence of cough headache or non-cough headache, brainstem and cranial nerve symptoms, and presence of paresthesia, dysesthesia, bladder incontinence, dysphagia, motor deficits (weakness, atrophy, or spasticity), sensory deficits (hypesthesia or posterior column dysfunction), abnormal reflexes, gait instability, and cerebellar signs.

A uniform MRI protocol was followed for all CMI patients, with the patient's neck kept in a neutral position. The radiological variables recorded on MRI included degree of tonsillar descent below the FM (Fig. 1A), ${ }^{10,27}$ characteristics of the syrinx (diameter, levels, location, and type; i.e., central, enlarged, or deviated) (Fig. 1B-D), ${ }^{20,21}$ presence or absence of scoliosis, maximum axial width of the fourth ventricle, ${ }^{30}$ odontoid retroversion (angle between the base of C-2 and its intersection with a line from the odontoid tip) (Fig. 2A), retroflexion (angle formed between a line drawn through the odontoid synchondrosis and its intersection with a line drawn from the odontoid tip) (Fig. 2B), ${ }^{5,31}$ clivus-canal angle (angle between Wackenheim's clivus line and the posterior wall of the C-2 vertebral body) (Fig. 2C), ${ }^{25} \mathrm{pB}-\mathrm{C} 2$ distance (perpendicular distance between the ventral dura to the line that joins the basion to the posterior portion of the axis body inferior endplate) (Fig. 3A), ${ }^{11,17}$ obex position (the distance between the obex and the basion-opisthion line) (Fig. 3B), ${ }^{12,28}$ cervicomedullary angle (Fig. 3C), posterior fossa morphometric variables (like the dimensions of the FM and the posterior fossa volume (PFV)/intracranial volume (ICV) ratio determined using the following formulas: $\mathrm{PFV}=$ $4 / 3 \pi(\mathrm{x} / 2 \times \mathrm{y} / 2 \times \mathrm{z} / 2)$ and ICV $=948+(0.478 \times$ [area of FM in $\left.\mathrm{mm}^{2}\right)^{2}$ (Fig. 4), ${ }^{8}$ hindbrain morphometric variables (the L-line was a line drawn across the clivus vertex parallel to the C-2 endplate, while the M-line was drawn perpendicular to this; the distances from each of these lines were measured to the pontobulbar sulcus, fourth ventricle vertex [FVV], and tonsillar tip) (Fig. 5), ${ }^{33} \mathrm{C} 2-7$ sagittal alignment (Cobb angle between the lines along the lower endplates of C-2 and C-7) (Fig. 6A), ${ }^{15}$ and the cervical taper ratio (tapering of the anteroposterior spinal canal dimension from C-1 to C-7, with the slope of the obtained linear trend line recorded as the taper ratio in millimeters per level) (Fig. 6B)..$^{14}$

\section{Outcome Assessment}

Clinical outcome at the last follow-up was measured using a validated multifactorial outcome measure, the Chicago Chiari Outcome Scale (CCOS), ${ }^{1}$ which is measured on a scale from 4 to 16 . Radiological outcome was measured as the percentage of regression of syringomyelia on MRI using the following formula: [(preoperative syrinx/cord ratio - follow-up syrinx/cord ratio) $\times 100] /($ preoperative syrinx/cord ratio). Syrinx resolution was defined as $100 \%$ regression of syrinx at follow-up.

\section{Statistical Analysis}

Using the subjects-to-variables rule of 10 (i.e., having at least 10 patients per variable in the instrument being used), in the multiple linear regression analysis a sample size of 57 patients in the study cohort was found to be adequate for generation of the regression model with a 


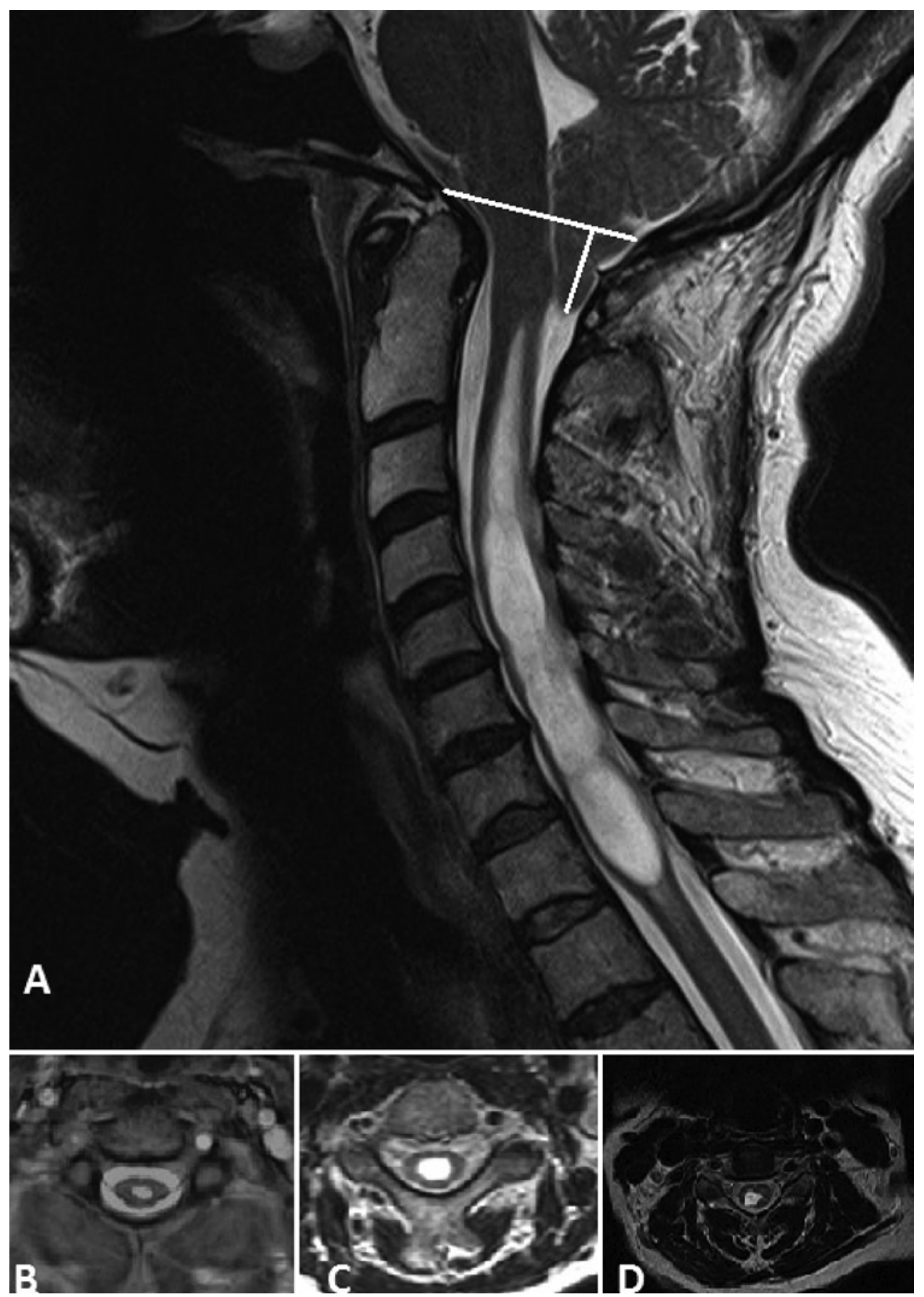

FIG. 1. A: The degree of tonsillar descent noted as the distance of the tonsillar tip from the FM on a paramedian sagittal MRI section. B-D: Central (B), enlarged (C), and deviated (D) syringes depending on their location in the cord are seen on T2-weighted axial MR images.

power of $90 \%$. Of the 82 patients included in the study, the study or test cohort consisted of 57 consecutive patients, while the validation cohort consisted of the remaining 25 patients. Continuous variables are expressed as the mean \pm SD with range, while frequency distributions were used to describe the categorical variables. Hypothesis testing was done at each stage to remove outliers, assess normality, and check correlations. The Anderson normality test was used to assess the normality of the distribution of the variables. Dixon's Q test was used for the identification and rejection of outliers.

Bivariate analysis (using the chi-square test, Pearson's correlation, Kendall's rank correlation, or Spearman's correlation test) was done to identify the preoperative variables that correlated with the outcome measures. Multiple linear regression analysis was then performed using the variables with $\mathrm{p}<0.05$ on the bivariate analysis to check for their independent associations with the outcome mea- 


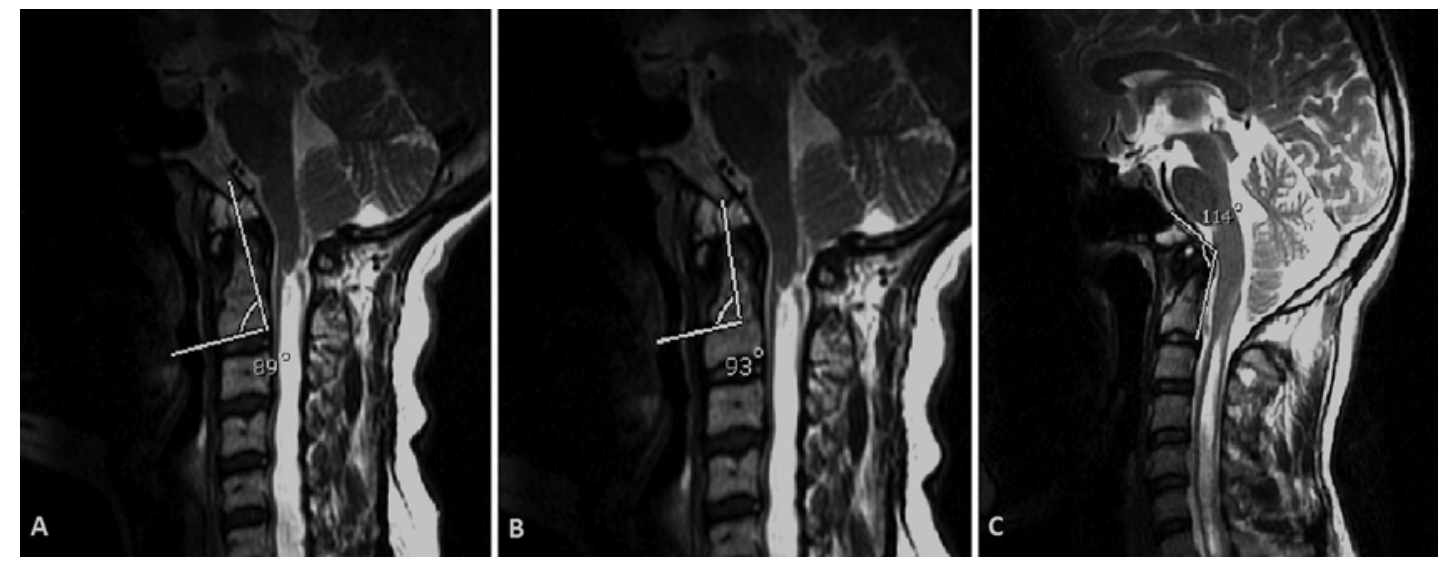

FIG. 2. A: Odontoid retroversion measured as the angle between the base of $\mathrm{C}-2$ and its intersection with a line drawn from the odontoid tip. B: Odontoid retroflexion measured as the angle formed between a line drawn through the odontoid synchondrosis and its intersection with a line drawn from the odontoid tip. C: Clivus-canal angle measured as the angle between Wackenheim's clivus line and the posterior wall of the C-2 vertebral body.

sures. A points-based system was developed that employed the regression coefficients obtained by the regression model to quantify the impact of each predictor on achieving a cure, with the intercept taken as the constant. Receiver operating characteristic (ROC) curves were generated to calculate the area under the curve (AUC) of different regression models, identify optimal thresholds, and calculate sensitivity, specificity, and predictive values. The model with the best predictive value was identified and validated. For the ROC analysis, a CCOS score of 11 and greater was taken as the cutoff value for clinical improvement, as reported previously. ${ }^{13}$ Cohen's kappa coefficient analysis was used to measure the interrater reliability of the model. Statistical software (SPSS version 17.0 for Windows; IBM) was used for the data analysis.

\section{Results}

\section{Demographic and Preoperative Clinicoradiological Characteristics}

There were 30 male and 27 female patients in the study cohort with a mean \pm SD age of $38.29 \pm 14.32$ years (range 22-66 years). The mean duration of symptoms was 29.81 \pm 12.71 months (range $1-272$ months). The preoperative clinical and radiological characteristics of the cohort are listed in Tables 1 and 2, respectively.

\section{Clinicoradiological Characteristics at Follow-Up}

The mean follow-up period was $40.29 \pm 10.36$ months (range 6-53 months). Syrinx resolved in 4 patients $(7 \%)$ and regressed partially in 35 patients $(61.40 \%)$. Of the 18 patients $(31.57 \%)$ in whom syrinx remained the same or had worsened at the last follow-up, 10 patients with clinical worsening received a syringopleural shunt, while the remaining 8 patients were clinically stable and conservatively monitored.

Syrinx diameter decreased from a preoperative mean \pm SD value of $6.86 \pm 2.55 \mathrm{~mm}$ to $2.88 \pm 1.21 \mathrm{~mm}$ at the last follow-up. Hindbrain CSF flow on cine MRI normalized in 52 patients $(91.22 \%)$ at follow-up.

Analysis of the predominant preoperative clinical fea-
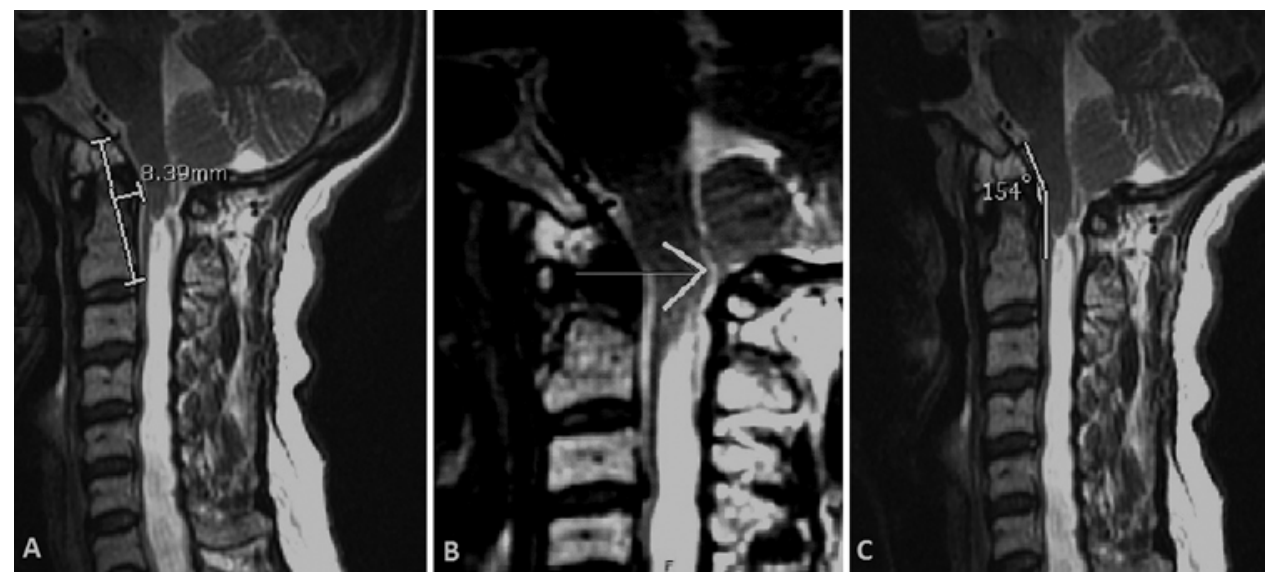

FIG. 3. A: $\mathrm{pB}-\mathrm{C} 2$ distance measured as the perpendicular distance between the ventral dura to the line that joins the basion and the posterior portion of the axis body inferior endplate. B: Obex position (arrow) recorded as the distance between the obex and the basion-opisthion line. C: Cervicomedullary angle defined as the angle subtended by the lines drawn along the ventral surfaces of the medulla and upper cervical cord. 

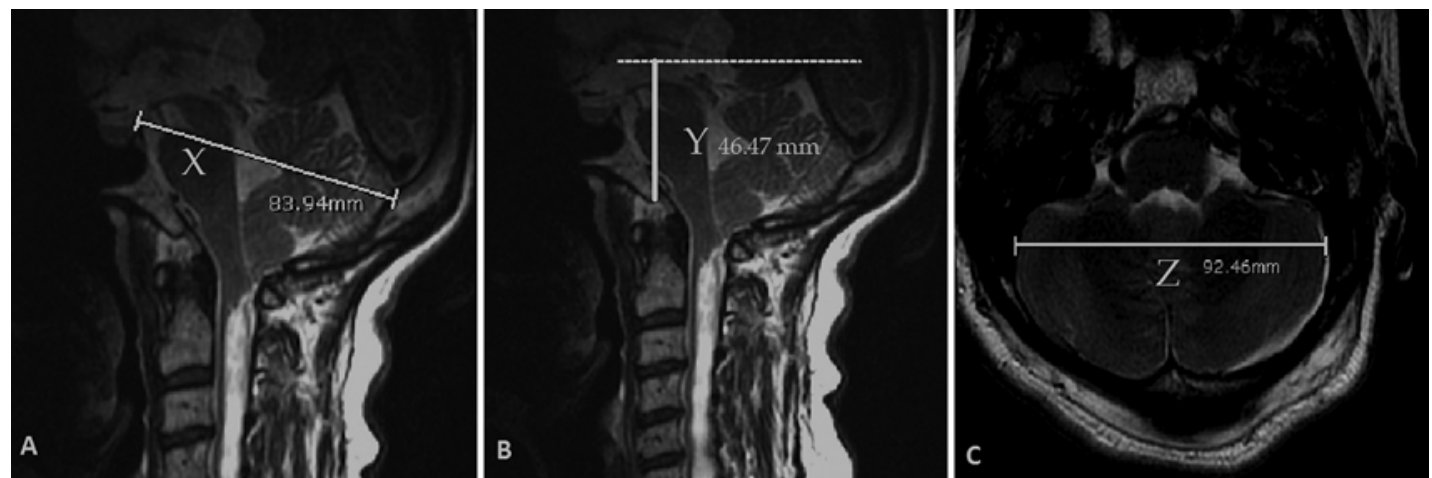

FIG. 4. Posterior fossa morphometric variables. A: Distance from the posterior clinoid to the confluence of sinuses (X). B: Distance from the basion to the peak of the tentorium $(Y)$. C: Maximum width of the posterior fossa $(Z)$.

tures revealed that at the last follow-up, cough headache improved in 25 of 25 patients $(100 \%)$, neck pain in 21 of 28 patients $(75 \%)$, abnormal reflexes in 12 of 25 patients (48\%), gait instability in 11 of 24 patients $(45.83 \%)$, sensory deficits in 10 of 27 patients $(37 \%)$, motor deficits in 12 of 40 patients (30\%), paresthesia in 9 of 28 patients (32.14\%), and dysesthesia in 3 of 14 patients $(21.42 \%)$. The total CCOS scores ranged from 4 to 16 . Five patients scored less than 11 on CCOS, while 29 patients scored between 11 and 13, and 23 patients scored 14 or greater.

\section{Bivariate Analysis}

Among the various clinical and radiological variables tested for associations with CCOS score and syrinx regression (Table 3), motor deficits, gait instability, and the M-Line-FVV distance were correlated with CCOS score $(\mathrm{p} \leq 0.05)$, while motor deficits, abnormal reflexes, and the PFV/ICV ratio were correlated with syrinx regression $(\mathrm{p}<0.05)$. Tonsillar shrinkage (performed in 8 patients) was not found to have any correlation with either of the outcome measures. None of the clinical or radiological variables correlated significantly with the syrinx nonreduction or expansion seen in 18 patients. There was no correlation between CCOS and syrinx regression $(\mathrm{p}=0.24)$.

\section{Multiple Regression Analysis}

A multiple linear regression analysis (using the variables that had significant correlations with the outcome measures on the bivariate analysis) demonstrated gait instability, obex position, and M-line-FVV distance to be independently associated with CCOS score (Table 4). The ANOVA results and goodness-of-fit of the regression model are presented in Tables 5 and 6, respectively. The presence of motor deficits alone correlated with poor syrinx regression (Table 7).

\section{Post Hoc Analysis}

The radiological variables that were significant in the multiple regression analysis were analyzed for postoperative changes and correlations with other variables. The obex position demonstrated cranial displacement from the FM from a preoperative mean \pm SD of $7.96 \pm 3.12 \mathrm{~mm}$ to $8.33 \pm 3.51 \mathrm{~mm}$ at follow-up $(\mathrm{p}=0.55)$, while FVV shifted posteriorly from a preoperative M-line-FVV distance of $22.41 \pm 6.01 \mathrm{~mm}$ to $23.46 \pm 6.79 \mathrm{~mm}(\mathrm{p}=0.38)$ at followup. The obex position correlated inversely with C-2 retroflexion (0.008), and the M-line-FVV distance correlated with the PFV/ICV ratio $(p=0.05)$. There was no correlation between age and either of these variables $(p=0.47$ and 0.59 , respectively).

\section{Prediction Model for CCOS Scores}

We multiplied the regression coefficients from our linear regression model by 10 and rounded them to the nearest integer to use them as weights. We obtained the following weights for the variables that were significant in our regression model: gait instability $=-10$; obex position $=-1$; M-line-FVV distance $=-1$; intercept $=162$. Points were calculated for each individual by multiplying the weights against their values for each of these variables and summed to obtain the total score. We tested different models for their ability to predict CCOS scores.

The best prediction model was: total points $=162-[10 \mathrm{a}$ $+1 b+1 c]$, where $a=$ absence or presence of gait instability ( 0 or 1 , respectively), $b=$ obex position in millimeters, and $\mathrm{c}=\mathrm{M}$-line-FVV distance in millimeters. Thus, patients with no gait instability, a caudally located cervicomedullary junction (i.e., the obex was closer to the FM), and a shorter M-line-FVV distance would score higher on this model.
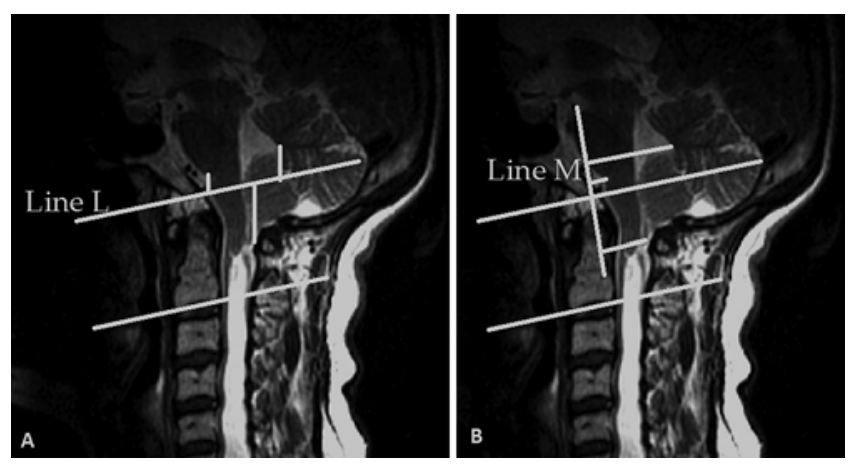

FIG. 5. Hindbrain morphometric variables. A: Line $L$ is drawn across the clivus vertex and parallel to the $\mathrm{C}-2$ endplate. $\mathrm{B}$ : Line $M$ is drawn perpendicular to the L-line. The distances from each of these lines to the pontobulbar sulcus, FVV, and tonsillar tip were measured. 


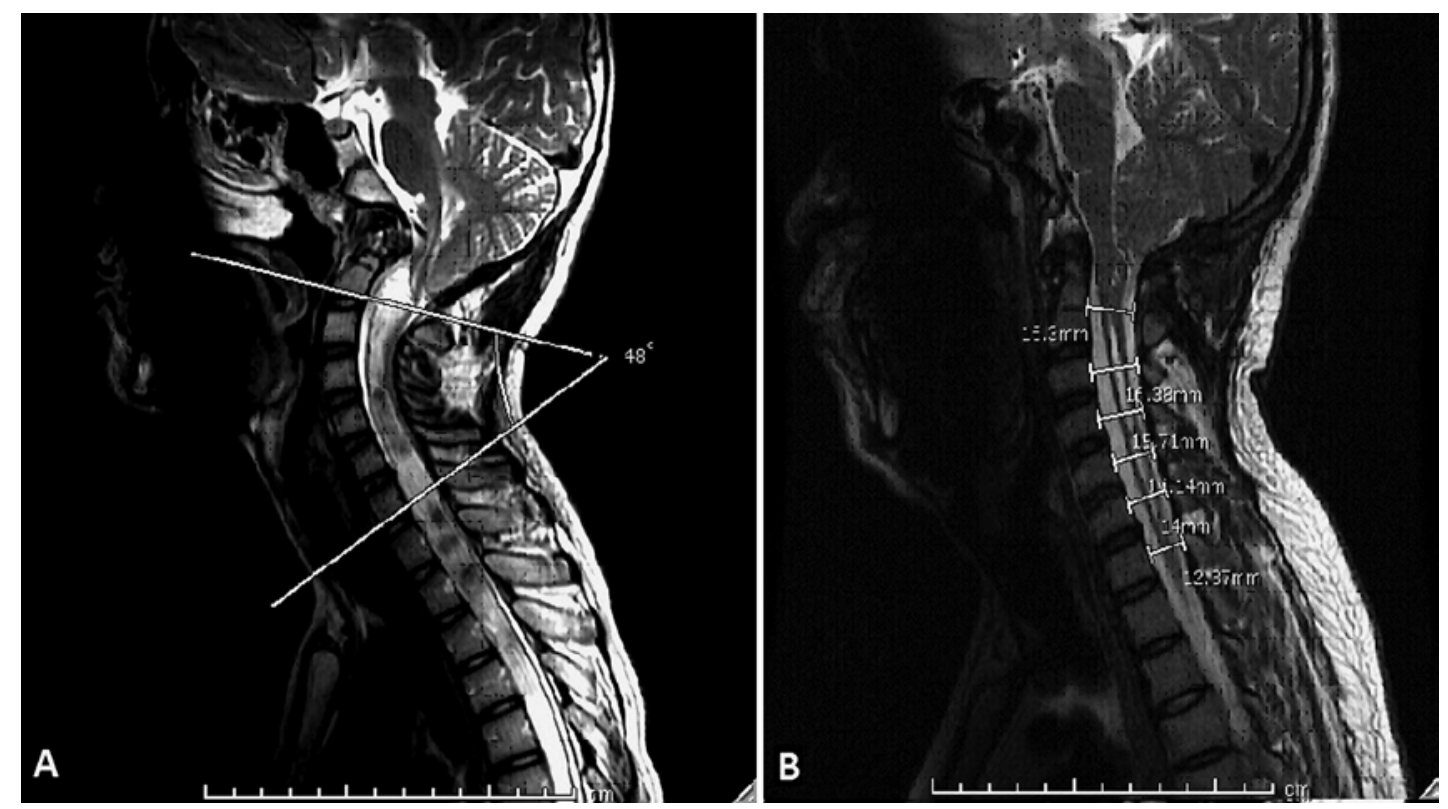

FIG. 6. A: C2-7 sagittal alignment measured as the Cobb angle between the lines along the lower endplates of C-2 and C-7. B: Cervical taper ratio measured as the tapering of the anteroposterior spinal canal dimension from C-1 to C-7.

\section{Performance and Validation of the Model}

We performed an ROC analysis with the total score obtained using the model and compared it against clinical improvement (Fig. 7). The AUC (0.81) obtained an optimal threshold score of 128 points, which had a sensitivity of $62 \%$ (i.e., 3 of 5 patients with scores $<128$ points would

TABLE 1. Clinical features of the study cohort

\begin{tabular}{lc}
\hline \multicolumn{1}{c}{ Feature } & Value \\
\hline Age, mean \pm SD, yrs & $38.29 \pm 14.32$ \\
\hline Sex & $30(52.63)$ \\
\hline Male & $27(47.36)$ \\
\hline Female & $29.81 \pm 12.71$ \\
\hline Duration of symptoms, mean \pm SD, mos & $41(71.92)$ \\
\hline Motor deficits & $27(47.37)$ \\
\hline Sensory deficits & $28(49.12)$ \\
\hline Neck pain & $28(49.12)$ \\
\hline Paresthesia & $25(43.86)$ \\
\hline Abnormal reflexes & $25(43.86)$ \\
\hline Cough headache & $24(42.10)$ \\
\hline Gait instability & $14(24.56)$ \\
\hline Dysesthesia & $6(10.53)$ \\
\hline Bladder dysfunction & $6(10.53)$ \\
\hline Cranial nerve symptoms & $6(10.53)$ \\
\hline Non-cough headache & $3(5.26)$ \\
\hline Cerebellar signs & $2(3.51)$ \\
\hline Brainstem signs & $1(1.75)$ \\
\hline Dysphagia & $0(0)$ \\
\hline Drop attacks &
\end{tabular}

Values are given as the number of patients (\%) unless indicated otherwise. be correctly identified as having a worse clinical outcome [CCOS score less than 11]) and a specificity of $100 \%$ (i.e., all patients with scores $>128$ points on the model would demonstrate a CCOS score of 11 or greater). For example, a patient with no gait instability, an obex position of 5.4 $\mathrm{mm}$ from the FM, and an M-line-FVV distance of 22.2 $\mathrm{mm}$ (Fig. 8) scored 134 points on the model, thereby suggesting clinical improvement. This patient's CCOS score of 15 corroborated the accuracy of the score from the predictive model. The model was internally validated on a cohort of 25 patients and was found to have fair accuracy for predicting better clinical outcomes (AUC 0.75). Interrater reliability analysis of the model demonstrated $\kappa=0.85$, indicating excellent agreement.

\section{Complications}

There were 6 transient postoperative complications in the study cohort: 1 case (1.75\%) each of aseptic meningitis and wound infection, and 2 cases (3.5\%) each of CSF leak and pseudomeningocele. One $(1.75 \%)$ patient developed persistent vomiting that resolved with conservative measures.

\section{Discussion}

\section{Predictive Variables Identified in Previous CMI Studies}

A large number of studies have analyzed different sets of preoperative variables in relation to clinical and radiological outcomes after CMI surgery, and varying results have been published. While sex, age, duration of followup, tonsillar and syrinx characteristics, ${ }^{21-23,32}$ and $\mathrm{pB}-\mathrm{C} 2$ distance ${ }^{17}$ have been demonstrated to be associated with syrinx resolution in some studies, 1 study considered multiple variables ${ }^{30}$ and found none to be associated with radiological outcome. The results with regard to clinical outcomes have been similarly diverse, with variables like 
TABLE 2. Radiological variables of the study cohort

\begin{tabular}{|c|c|}
\hline Variable & Value \\
\hline \multicolumn{2}{|l|}{ Syrinx location, $\mathrm{n}(\%)$} \\
\hline Cervical & $8(14.03)$ \\
\hline Cervicothoracic & $38(66.66)$ \\
\hline Thoracic & $1(1.75)$ \\
\hline Holocord & $10(17.54)$ \\
\hline \multicolumn{2}{|l|}{ Syrinx type, n (\%) } \\
\hline Central & $6(10.53)$ \\
\hline Enlarged & $45(78.94)$ \\
\hline Deviated & $6(10.53)$ \\
\hline Scoliosis, $n(\%)$ & $17(29.82)$ \\
\hline Syrinx levels & $12.23 \pm 4.67$ \\
\hline Tonsillar herniation & $18.53 \pm 6.78$ \\
\hline Syrinx/cord ratio & $0.75 \pm 0.17$ \\
\hline 4th ventricle width, $\mathrm{mm}$ & $12.48 \pm 4.99$ \\
\hline C-2 retroversion, deg & $104.69 \pm 8.52$ \\
\hline C-2 retroflexion, deg & $101.28 \pm 7.29$ \\
\hline Clivus-canal angle, deg & $135.29 \pm 10.98$ \\
\hline Cerebellomedullary angle, deg & $148.48 \pm 10.92$ \\
\hline $\mathrm{pB}-\mathrm{C} 2$ distance, $\mathrm{mm}$ & $4.54 \pm 2.31$ \\
\hline Obex position relative to $\mathrm{FM}, \mathrm{mm}$ & $7.96 \pm 3.12$ \\
\hline \multicolumn{2}{|l|}{ FM dimensions, $\mathrm{mm}$} \\
\hline Anteroposterior, i.e., McRae line & $31.93 \pm 4.89$ \\
\hline Lateral & $28.01 \pm 3.82$ \\
\hline PFV/ICV ratio & $153.00 \pm 28.76$ \\
\hline L-line-bulbopontine sulcus distance, $\mathrm{mm}$ & $12.19 \pm 3.28$ \\
\hline L-line-FVV distance, $\mathrm{mm}$ & $21.50 \pm 5.49$ \\
\hline L-line-tonsillar tip distance, $\mathrm{mm}$ & $17.37 \pm 7.81$ \\
\hline M-line-bulbopontine sulcus distance, $\mathrm{mm}$ & $2.13 \pm 3.31$ \\
\hline M-line-FVV distance, $\mathrm{mm}$ & $22.41 \pm 6.01$ \\
\hline M-line-tonsillar tip distance, $\mathrm{mm}$ & $21.16 \pm 4.51$ \\
\hline C2-7 sagittal angle, deg & $13.48 \pm 12.48$ \\
\hline Cervical taper ratio & $-0.51 \pm 0.47$ \\
\hline
\end{tabular}

Values are shown as the mean \pm SD unless indicated otherwise.

duration of symptoms, ${ }^{2,7}$ nystagmus, ${ }^{7}$ trigeminal hypesthesia, ${ }^{7}$ sensory deficits, ${ }^{7,13}$ cough headache ${ }^{6,12,18}$ myelopathy ${ }^{12}$ syrinx diameter, ${ }^{12} \mathrm{pB}-\mathrm{C} 2$ distance,${ }^{17} \mathrm{CSF}$ flow ${ }^{19} \mathrm{PFV},{ }^{4}$ and spinal cord diameter ${ }^{9}$ established as being correlated with outcomes. Of the few PSM-based studies on CMI, 1 study determined atrophy, ataxia, and scoliosis to be predictive of long-term outcome on a clinical ranking model, ${ }^{7}$ while a grading system for Chiari malformation severity identified headache characteristics, myelopathy, and syrinx diameter of more than $6 \mathrm{~mm}$ as having the strongest impact on gestalt patient-perceived outcomes. ${ }^{12}$

\section{Unconventional Radiological Variables in CMI}

Moving from the traditionally analyzed variables in CMI, there has been recent interest in variables related to the cervical spine, such as cervical sagittal alignment ${ }^{15}$ and the cervical taper ratio,${ }^{14}$ but these have not been analyzed
TABLE 3. Bivariate correlations between patient variables, CCOS score, and syrinx regression

\begin{tabular}{|c|c|c|}
\hline \multirow[b]{2}{*}{ Variable } & \multicolumn{2}{|c|}{$p$ Value } \\
\hline & ccos Score & Syrinx Regression \\
\hline Age & 0.24 & 0.93 \\
\hline Sex & 0.52 & 0.83 \\
\hline Body mass index & 0.84 & 0.85 \\
\hline Duration of symptoms & 0.37 & 0.73 \\
\hline Neck pain & 0.76 & 0.15 \\
\hline Cough headache & 0.25 & 0.07 \\
\hline Non-cough headache & 0.83 & 0.68 \\
\hline Paresthesia & 0.73 & 0.54 \\
\hline Dysesthesia & 0.56 & 0.67 \\
\hline Brainstem symptoms & 0.40 & 0.78 \\
\hline Cranial nerve symptoms & 0.83 & 0.59 \\
\hline Dysphagia & 0.97 & 0.42 \\
\hline Bladder dysfunction & 0.96 & 0.80 \\
\hline Motor deficits & 0.04 & 0.00 \\
\hline Sensory deficits & 0.20 & 0.62 \\
\hline Abnormal reflexes & 0.50 & 0.04 \\
\hline Cerebellar signs & 0.45 & 0.22 \\
\hline Gait instability & 0.03 & 0.42 \\
\hline Syrinx location & 0.59 & 0.13 \\
\hline Syrinx type & 0.71 & 0.43 \\
\hline Syrinx levels & 0.39 & 0.12 \\
\hline Scoliosis & 0.15 & 0.87 \\
\hline Tonsillar herniation & 0.33 & 0.46 \\
\hline Syrinx/cord ratio & 0.21 & 0.27 \\
\hline 4th ventricle width & 0.72 & 0.63 \\
\hline C-2 retroversion & 0.53 & 0.75 \\
\hline C-2 retroflexion & 0.57 & 0.17 \\
\hline Clival canal angle & 0.24 & 0.96 \\
\hline Cerebellomedullary angle & 0.29 & 0.16 \\
\hline $\mathrm{pB}-\mathrm{C} 2$ line & 0.59 & 0.23 \\
\hline Obex position & 0.10 & 0.55 \\
\hline McRae line length & 0.21 & 0.44 \\
\hline FM lateral dimension & 0.53 & 0.31 \\
\hline PFV/ICV ratio & 0.60 & 0.01 \\
\hline $\begin{array}{l}\text { L-line-bulbopontine sulcus } \\
\text { distance }\end{array}$ & 0.84 & 0.81 \\
\hline L-line-FVV distance & 0.59 & 0.94 \\
\hline L-line-tonsillar tip distance & 0.69 & 0.31 \\
\hline $\begin{array}{l}\text { M-line-bulbopontine sulcus } \\
\text { distance }\end{array}$ & 0.46 & 0.44 \\
\hline M-line-FVV distance & 0.05 & 0.46 \\
\hline M-line-tonsillar tip distance & 0.33 & 0.24 \\
\hline C2-7 sagittal angle & 0.12 & 0.13 \\
\hline Cervical taper ratio & 0.48 & 0.07 \\
\hline
\end{tabular}

Boldface type indicates statistical significance. 
TABLE 4. Multiple linear regression analysis for assessing independent correlations with CCOS score

\begin{tabular}{lccc}
\hline \multicolumn{1}{c}{ Variable } & B & SE & p Value \\
\hline Constant & 16.25 & NA & NA \\
\hline Motor deficit & -0.47 & 0.44 & 0.31 \\
\hline Gait instability & -0.96 & 0.43 & $\mathbf{0 . 0 4}$ \\
\hline Obex position & -0.13 & 0.06 & $\mathbf{0 . 0 4}$ \\
\hline M-line-FVV distance & -0.08 & 0.04 & $\mathbf{0 . 0 5}$ \\
\hline
\end{tabular}

$\mathrm{B}=$ unstandardized coefficient; $\mathrm{NA}=$ not applicable; $\mathrm{SE}=$ standard error. Boldface type indicates statistical significance.

with respect to outcome in multivariable studies. Using these variables, in addition to conventional preoperative clinicoradiological variables, in one of the largest variable arrays used so far in CMI research, we attempted to generate an algorithm for predicting postoperative improvement on a validated outcome measure in CMI patients with restricted hindbrain CSF flow.

\section{Correlations of Preoperative Clinical Features With Outcome}

We found that the presence of motor deficits, abnormal reflexes, and gait instability correlated with outcome after CMI surgery. This has also been recognized in previous studies. ${ }^{7,12}$ It can be construed that by the time a patient with CMI develops these specific deficits, severe neurological dysfunction in the alpha motor neurons or corticospinal or dorsal column tracts has occurred to such a degree that surgery is unlikely to achieve a good radiological or clinical outcome. Contrary to previous reports, ${ }^{3,7,12,13}$ we found that neither cough headache nor any sensory symptoms or deficits were correlated with outcome. There was no correlation between clinical improvement and syrinx regression in our study. This finding has been previously described, ${ }^{9}$ wherein it was noted that while the cord diameter per se correlated with clinical improvement, the syrinx-cord ratio did not. This was hypothesized to be due to differential rates in the reduction in the cord and syrinx diameters following surgery.

\section{Correlations of Preoperative Radiological Variables With CMI Outcome}

The hindbrain and posterior fossa morphometric variables that correlated with outcome in our study included the PFV/ICV ratio for its correlation with syrinx regression, and the obex position and M-line-FVV distance for their correlations with CCOS score.

Posterior fossa morphometry has been demonstrated to

TABLE 5. Analysis of variance with respect to CCOS score

\begin{tabular}{lcrccc}
\hline Variable & Sum of Squares & df & Mean Square & F & p Value \\
\hline Regression & 34.79 & 4 & 8.70 & 3.86 & 0.008 \\
\hline Residual & 117.14 & 52 & 2.25 & NA & NA \\
\hline Total & 151.93 & 53 & NA & NA & NA \\
\hline
\end{tabular}

$\mathrm{df}=$ degrees of freedom.
TABLE 6. Goodness-of-fit analysis of the model

\begin{tabular}{ll}
\hline \multicolumn{1}{c}{ Variable } & Value \\
\hline $\mathrm{R}$ & 0.68 \\
\hline $\mathrm{R}$ square & 0.46 \\
\hline Adjusted $\mathrm{R}$ square & 0.4 \\
\hline $\mathrm{SE}$ & 1.5 \\
\hline
\end{tabular}

be altered in $\mathrm{CMI},{ }^{8}$ with evidence that patients with decreased posterior fossa size respond better to decompressive surgery than their normal-sized counterparts. ${ }^{4}$ Our finding of a smaller PFV/ICV ratio correlated with better syrinx regression is consistent with this observation.

The position of the obex or the cervicomedullary junction in relation to the FM in patients with CMI has been studied previously ${ }_{12}^{12}$ with caudal displacement construed as a marker of CMI severity and risk for progression to Chiari malformation Type 1.5 in untreated cases. ${ }^{16}$ The 8-mm mean distance of the obex from the FM in our patient cohort was less than the 10- to $12-\mathrm{mm}$ distance observed in healthy populations. ${ }^{24,29}$ This suggests that, along with the classic tonsillar descent in CMI, the cervicomedullary junction also tends to be caudally displaced toward the FM.

The M-line-FVV distance is a marker of the position of the deformed cerebellum in the crowded posterior fossa. ${ }^{33}$ We noted an inverse relationship between M-lineFVV distance and CCOS. A previous study ${ }^{33}$ noted various shifts in hindbrain morphometric lines after surgery as indicative of the deformed cerebellum reverting to its normal morphology. Our patients also demonstrated a backward shift in FVV after surgery, although this might not be significant enough in view of the relatively short follow-up period.

\section{The "Worse is Better" Radiological Paradigm in CMI}

Some studies have documented markers of worse hindbrain pathology in patients with CMI, such as poor CSF flow, ${ }^{19}$ smaller $\mathrm{PFV},{ }^{4}$ and a $\mathrm{pB}-\mathrm{C} 2$ distance $>3 \mathrm{~mm},{ }^{17}$ as being associated with better outcomes after surgery. The consensus of these studies is that the more severe the hindbrain CSF flow, either due to a smaller posterior fossa or ventral encroachment by an angulated odontoid, the more direct its pathoetiological role in symptomatology and the better the response to decompressive surgery.

TABLE 7. Multiple linear regression analysis for assessing independent correlations with syrinx regression

\begin{tabular}{lccc}
\hline \multicolumn{1}{c}{ Variable } & B & SE & p Value \\
\hline Constant & 85.88 & NA & NA \\
\hline Cough headache & 13.68 & 10.98 & 0.23 \\
\hline Abnormal reflexes & -14.27 & 8.72 & 0.10 \\
\hline Motor deficits & -34.41 & 9.57 & $\mathbf{0 . 0 0 2}$ \\
\hline PFV/ICV ratio & -0.26 & 0.17 & 0.12 \\
\hline Cervical taper ratio & -12.72 & 8.77 & 0.15 \\
\hline
\end{tabular}

Boldface type indicates statistical significance. 


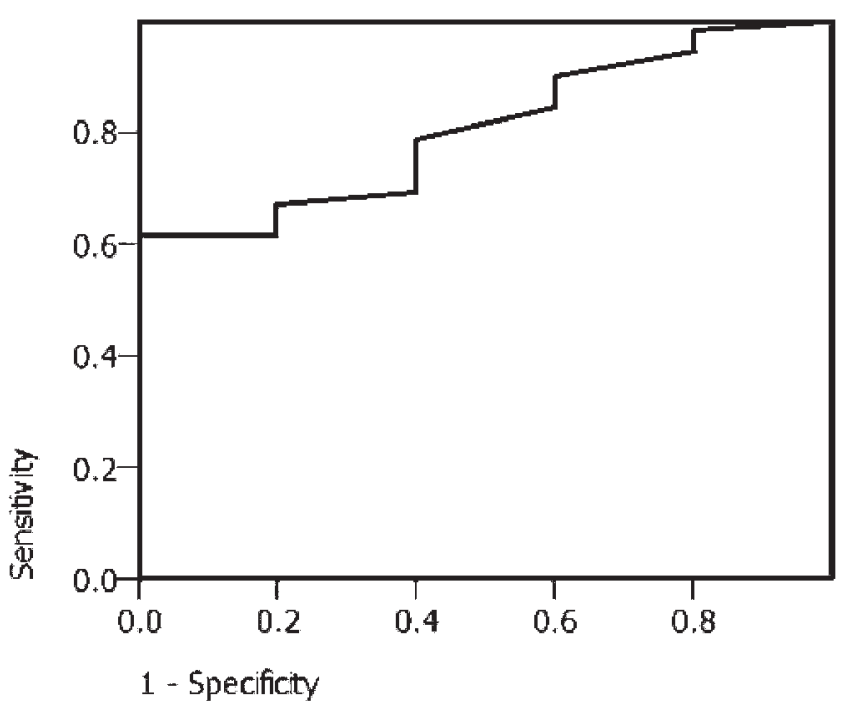

FIG. 7. ROC curve (AUC 0.81) of the points-based system and its ability to predict clinical improvement (i.e., CCOS score of 11 and greater).

After adjusting for multiple variables, our study identified 2 novel preoperative markers-the obex position and the M-line-FVV distance - that corroborate the "worse is better" radiological paradigm in CMI. Caudal displacement of the obex (i.e., a shorter distance from the FM) can be considered a marker of disease severity in CMI, as alluded to earlier. Given the fact that posterior fossa overcrowding is considered a hallmark of CMI, it can be inferred that a smaller M-line-FVV distance correlated with a smaller PFV/ICV ratio is indicative of a smaller ratio being a marker of worse anomalous hindbrain morphology. Smaller values for both of these novel preoperative markers translated to better CCOS scores at follow-up.

\section{Our Predictive Algorithm}

CCOS - the only validated outcome measure for CMIis a composite score consisting of 4 subscores pertaining to pain, nonpain symptoms, functionality, and complications. It has proven to be more reliable than the usual gestalt impressions of outcome that have been used so far in CMI research. While a previous study analyzed preoperative clinical variables with respect to CCOS score, ${ }^{13}$ ours is the first study, to our knowledge, that used both clinical and radiological variables to generate a pointsbased model for predicting scores on this robust outcome measure. We reemphasize that a score $\geq 128$ points based on the presence or absence of gait instability and the 2 novel radiological markers of this model predict clinical improvement at follow-up with a specificity of $100 \%$ and sensitivity of $62 \%$. This validated and reliable scoring system is unique in its simplicity and ease of use, and it has good predictive power.

\section{Limitations}

The study has the inherent limitations of a retrospective analysis and is prone to errors due to inconsistent or inaccurate medical records. The algorithm that we provided is based on the physician's interpretations rather than

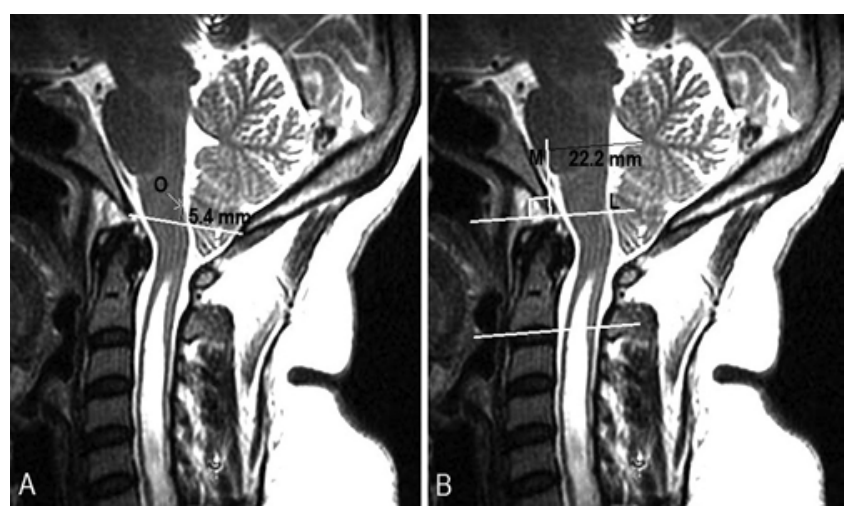

FIG. 8. Preoperative sagittal T2-weighted MRI of the cervicomedullary junction of a patient with no gait instability. A: The obex $(0)$ is located $5.4 \mathrm{~mm}$ from the basion-opisthion line. B: The FVV is $22.2 \mathrm{~mm}$ from the $M$-line $(M)$, a line crossing the clivus vertex and perpendicular with the $\mathrm{L}$-line $(\mathrm{L})$ that crosses the clivus vertex and is parallel with the $\mathrm{C}-2$ vertebral endplate. Using these values in the points-based system, this patient obtained a score of 134 points, indicating clinical improvement. This was corroborated by a CCOS score of 15 .

the patient's perception of improvement. While CCOS is a validated, multifactorial outcome measure for CMI, it has the drawback of being a retrospective, provider-based scoring system. The study does not address gradual or delayed clinical improvement, which may translate to CCOS scores improving with longer follow-up periods. Thus, it may be cautioned that the predictive value of this model holds good for a relatively short follow-up period of around 3 years. Furthermore, our results will need external validation in larger sample sizes and different patient populations.

\section{Conclusions}

The presence of gait imbalance and motor deficits independently predict a worse clinical and radiological outcome, respectively, after decompressive surgery for CMI with altered hindbrain CSF flow. Caudal displacement of the obex and a shorter M-line-FVV distance correlated with good CCOS scores, indicating that patients with worse hindbrain pathology respond better to surgery. The validated and reliable points-based algorithm that we propose has good predictive value for postoperative multifactorial outcome in these patients.

\section{References}

1. Aliaga L, Hekman KE, Yassari R, Straus D, Luther G, Chen J, et al: A novel scoring system for assessing Chiari malformation type I treatment outcomes. Neurosurgery 70:656665,2012

2. Attal N, Parker F, Tadié M, Aghakani N, Bouhassira D: Effects of surgery on the sensory deficits of syringomyelia and predictors of outcome: a long term prospective study. J Neurol Neurosurg Psychiatry 75:1025-1030, 2004

3. Attenello FJ, McGirt MJ, Gathinji M, Datoo G, Atiba A, Weingart J, et al: Outcome of Chiari-associated syringomyelia after hindbrain decompression in children: analysis of 49 consecutive cases. Neurosurgery 62:1307-1313, 2008

4. Badie B, Mendoza D, Batzdorf U: Posterior fossa volume and response to suboccipital decompression in patients with Chiari I malformation. Neurosurgery 37:214-218, 1995 
5. Besachio DA, Khaleel Z, Shah LM: Odontoid process inclination in normal adults and in an adult population with Chiari malformation Type I. J Neurosurg Spine 23:701-706, 2015

6. Chavez A, Roguski M, Killeen A, Heilman C, Hwang S: Comparison of operative and non-operative outcomes based on surgical selection criteria for patients with Chiari I malformations. J Clin Neurosci 21:2201-2206, 2014

7. Dyste GN, Menezes AH, VanGilder JC: Symptomatic Chiari malformations. An analysis of presentation, management, and long-term outcome. J Neurosurg 71:159-168, 1989

8. Furtado SV, Reddy K, Hegde AS: Posterior fossa morphometry in symptomatic pediatric and adult Chiari I malformation. J Clin Neurosci 16:1449-1454, 2009

9. Furtado SV, Thakar S, Hegde AS: Correlation of functional outcome and natural history with clinicoradiological factors in surgically managed pediatric Chiari I malformation. Neurosurgery 68:319-328, 2011

10. Godzik J, Kelly MP, Radmanesh A, Kim D, Holekamp TF, Smyth MD, et al: Relationship of syrinx size and tonsillar descent to spinal deformity in Chiari malformation Type I with associated syringomyelia. J Neurosurg Pediatr 13:368-374, 2014

11. Grabb PA, Mapstone TB, Oakes WJ: Ventral brain stem compression in pediatric and young adult patients with Chiari I malformations. Neurosurgery 44:520-528, 1999

12. Greenberg JK, Yarbrough CK, Radmanesh A, Godzik J, Yu M, Jeffe DB, et al: The Chiari Severity Index: a preoperative grading system for Chiari malformation type 1. Neurosurgery 76:279-285, 2015

13. Hekman KE, Aliaga L, Straus D, Luther A, Chen J, Sampat A, et al: Positive and negative predictors for good outcome after decompressive surgery for Chiari malformation type 1 as scored on the Chicago Chiari Outcome Scale. Neurol Res 34:694-700, 2012

14. Hirano M, Haughton V, Munoz del Rio A: Tapering of the cervical spinal canal in patients with Chiari I malformations. AJNR Am J Neuroradiol 33:1326-1330, 2012

15. Hyun SJ, Moon KY, Kwon JW, Lee CH, Kim J, Kim KJ, et al: Chiari I malformation associated with syringomyelia: can foramen magnum decompression lead to restore cervical alignment? Eur Spine J 22:2520-2525, 2013

16. Kim IK, Wang KC, Kim IO, Cho BK: Chiari 1.5 malformation: an advanced form of Chiari I malformation. J Korean Neurosurg Soc 48:375-379, 2010

17. Ladner TR, Dewan MC, Day MA, Shannon CN, Tomycz L, Tulipan N, et al: Evaluating the relationship of the pB-C2 line to clinical outcomes in a 15 -year single-center cohort of pediatric Chiari I malformation. J Neurosurg Pediatr 15:178-188, 2015

18. McGirt MJ, Attenello FJ, Atiba A, Garces-Ambrossi G, Datoo G, Weingart JD, et al: Symptom recurrence after suboccipital decompression for pediatric Chiari I malformation: analysis of 256 consecutive cases. Childs Nerv Syst 24:1333-1339, 2008

19. McGirt MJ, Nimjee SM, Fuchs HE, George TM: Relationship of cine phase-contrast magnetic resonance imaging with outcome after decompression for Chiari I malformations. Neurosurgery 59:140-146, 2006

20. Milhorat TH, Johnson RW, Milhorat RH, Capocelli AL Jr, Pevsner PH: Clinicopathological correlations in syringomyelia using axial magnetic resonance imaging. Neurosurgery 37:206-213, 1995

21. Nagoshi N, Iwanami A, Toyama Y, Nakamura M: Factors contributing to improvement of syringomyelia after foramen magnum decompression for Chiari type I malformation. J Orthop Sci 19:418-423, 2014
22. Navarro R, Olavarria G, Seshadri R, Gonzales-Portillo G, McLone DG, Tomita T: Surgical results of posterior fossa decompression for patients with Chiari I malformation. Childs Nerv Syst 20:349-356, 2004

23. Park YS, Kim DS, Shim KW, Kim JH, Choi JU: Factors contributing improvement of syringomyelia and surgical outcome in type I Chiari malformation. Childs Nerv Syst 25:453-459, 2009

24. Quisling RG, Quisling SG, Mickle JP: Obex/nucleus gracilis position: its role as a marker for the cervicomedullary junction. Pediatr Neurosurg 19:143-150, 1993

25. Smoker WR, Khanna G: Imaging the craniocervical junction. Childs Nerv Syst 24:1123-1145, 2008

26. Soroceanu A, Ching A, Abdu W, McGuire K: Relationship between preoperative expectations, satisfaction, and functional outcomes in patients undergoing lumbar and cervical spine surgery: a multicenter study. Spine (Phila Pa 1976) 37:E103-E108, 2012

27. Stovner LJ, Rinck P: Syringomyelia in Chiari malformation: relation to extent of cerebellar tissue herniation. Neurosurgery 31:913-917, 1992

28. Tubbs RS, Iskandar BJ, Bartolucci AA, Oakes WJ: A critical analysis of the Chiari 1.5 malformation. J Neurosurg 101 (2 Suppl):179-183, 2004

29. Tubbs RS, Smyth MD, Wellons JC III, Oakes WJ: Arachnoid veils and the Chiari I malformation. J Neurosurg 100 (5 Suppl Pediatrics):465-467, 2004

30. Tubbs RS, Webb DB, Oakes WJ: Persistent syringomyelia following pediatric Chiari I decompression: radiological and surgical findings. J Neurosurg 100 (5 Suppl Pediatrics):460-464, 2004

31. Tubbs RS, Wellons JC III, Blount JP, Grabb PA, Oakes WJ: Inclination of the odontoid process in the pediatric Chiari I malformation. J Neurosurg 98 (1 Suppl):43-49, 2003

32. Wu T, Zhu Z, Jiang J, Zheng X, Sun X, Qian B, et al: Syrinx resolution after posterior fossa decompression in patients with scoliosis secondary to Chiari malformation type I. Eur Spine J 21:1143-1150, 2012

33. Xie D, Qiu Y, Sha S, Liu Z, Jiang L, Yan H, et al: Syrinx resolution is correlated with the upward shifting of cerebellar tonsil following posterior fossa decompression in pediatric patients with Chiari malformation type I. Eur Spine J 24:155-161, 2015

\section{Disclosures}

The authors report no conflict of interest concerning the materials or methods used in this study or the findings specified in this paper.

\section{Author Contributions}

Conception and design: Thakar, Sai Kiran. Acquisition of data: Thakar, Sivaraju, Arun. Analysis and interpretation of data: Thakar, Jacob, Mohan. Drafting the article: Thakar, Aryan. Critically revising the article: Thakar, Aryan. Reviewed submitted version of manuscript: Thakar, Sivaraju, Arun, Aryan, Mohan, Sai Kiran, Hegde. Approved the final version of the manuscript on behalf of all authors: Thakar. Statistical analysis: Jacob. Administrative/ technical/material support: Hegde. Study supervision: Hegde.

\section{Correspondence}

Sumit Thakar, Department of Neurological Sciences, Sri Sathya Sai Institute of Higher Medical Sciences, Bangalore 560066, India.email: sumit.thakar@gmail.com. 